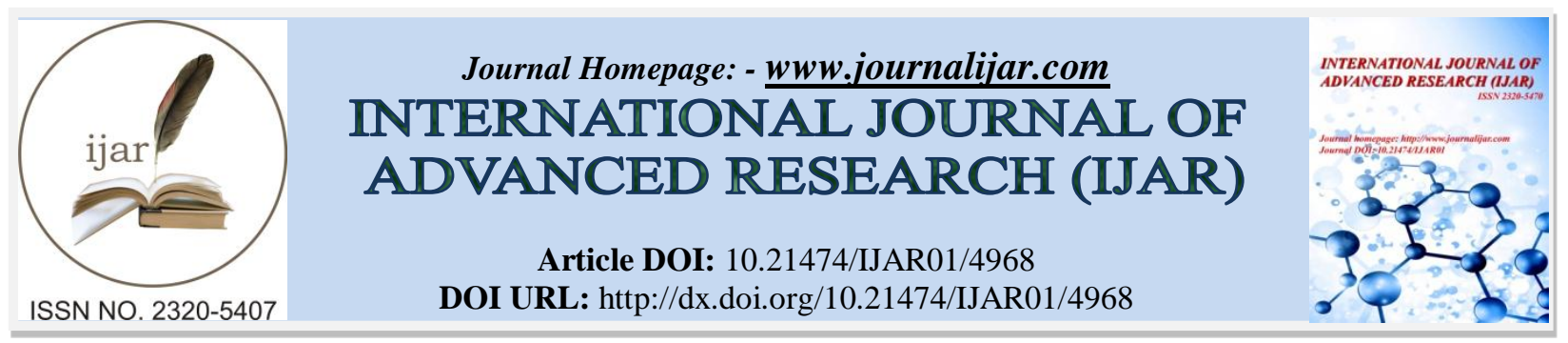

RESEARCH ARTICLE

\title{
ORGANIZATIONAL DEVELOPMENT IN BANKING INDUSTRY.
}

\author{
Dr. Chanderjeet.
}

\section{Manuscript Info}

Manuscript History

Received: 26 May 2017

Final Accepted: 28 June 2017

Published: July 2017

\section{Abstract}

The reason of this study is to explore the procedures of organizational development and procedures of responsiveness as useful for executives of banking industry. Another reason of this study is to find out the perceptions of different employees about Organizational development .The organizational atmosphere is people's observation and approach about the organization - whether it is good or bad place to work. Data was collected through personally administered questionnaires.
\end{abstract}

Copy Right, IJAR, 2017,. All rights reserved.

\section{Introduction:-}

Organization development (OD) is a response to change, a composite educational approach proposed to change the values, way of life, principles, structure of organization so that they can better familiarize yourself with new technologies, markets, and challenges with relevant changes itself. In this time of extreme struggle and globalization very few people will oppose that the success of any organization is a direct indication of its managerial efficiency and competence. It has been generally observed and extensively thought that organizational behavior, an area of organizational development is generally ignored in banking industry. A branch of management sciences with the name of organizational behavior, based on theories and models provide detailed information about the behaviors' and attitudes of people in organizational setup. Even though organizational development depends upon number of factors but to understand needs, concerns, and perceptions of employees the organizational climate needs to be assessed. Organizational climate refers to a set of measurable properties of the work environment, that are perceived by the people who live and work in it, and the influence their motivation and behavior. The banking organization atmosphere is people's observation and approach about the organization - whether it is good or bad place to work, friendly or unfriendly, hardworking or easy-going, and so forth where as the organization culture is the deep-seated assumptions, values, and beliefs that are enduring, often unconscious, and difficult to change. He also argued that atmosphere is relatively easy to change because it is built on employees perceptions.

\section{Review Of Literature:-}

Organizational development in the organizations is a big concern both for HR managers and the policy makers of the any type of organization and banking industry are not exception to this. To have a contented, motivated, less stressed performing workforce of banking organization must have reliability amongst its constitution, system, people, culture and good fit with the strategy. Effect of special factors on job satisfaction has been analyzed in the literature. Some studies focus on demographic determinants of workers job satisfaction but, the others relate it with nature of work and working conditions at the workplace. Similarly, fair promotion system in the banking organization, job autonomy, leadership behavior, social relations and the job itself are also among the important factors of job satisfaction. Employees' attitude towards their bank which has great effect towards their working ways and contributions, in consequence banking organization atmosphere causes bank performance because this 
relates directly to employees' motivation. The banking industry atmosphere is positively related to the job satisfaction and banking organization promise. The higher banking organizational atmosphere will lead to higher job satisfaction and more banking organization promise. For the success of banking, it is very significant to handle human resource efficiently and to find whether banking industry employees are satisfied or not. Workforce of any bank is responsible to a large level for its efficiency and success. Efficient human resource management and maintaining higher job satisfaction level in banks determine not only the performance of the bank but also affect the growth and performance of the entire banking industry economy. Although dominance of out dated system in any banks empowered work teams may work and increase, but ultimately it will require the revision to improve the current banking system.

\section{Objective Of The Study:-}

To examine the nature and concepts of organizational development through learning the perceptions of banking organization employee.

To examine awareness among the employees of banking organization.

To examine organizational development for both senior management of banking and HR department strategies as well as the betterment of banks output.

\section{Scope Of The Study:-}

The varying concept about the organization development of banking industry requires a new look at the concept of organization development performance .In the past, OD performance was defined in terms of a rise in the level of output of services with the same or reduced level of input as a result of better work methods and improved technology. It is, however, only though the employees that the ultimate increase in performance is achieved. Therefore, OD performance needed to be redefined in terms of employee motivation and satisfaction. Managing the employees today is an increasingly difficult task. The involvement, sincerity, creativity and dedication to the job that the management expects do not seem to be the outcome of financial incentives as was believed earlier.

\section{Limitations Of The Study:-}

Banking industry atmosphere is an insubstantial and slanted concept. Therefore it cannot be calculated directly. It can be measured only indirectly through opinions on responses to the various determinants. In the present study banking organization atmosphere is calculated with the help of respondents interview, questionnaire and schedule specifically designed.

\section{Data Analysis and Interpretation:-}

The present study is based on both primary data and secondary data. The main source of primary data is the collection of respondents employees interview and questionnaire received. To elicit information from the customers a schedule was designed and administered. The schedule was pre-tested and suitable modifications were carried out. The secondary data was collected from leading journals, magazines, newspapers, reports etc. A good number of standard text books was referred to obtain pertinent literature on the subject.

Table A:- Analysis Of Demographic Data Of The Banks

\begin{tabular}{|c|c|}
\hline GENDER & PERSENTAGE \\
\hline MALE & $\mathbf{7 5 \%}$ \\
\hline FEMALE & $\mathbf{2 5 \%}$ \\
\hline AGE GROUP (Averge) & $\mathbf{( 2 5 - 4 0 ) \mathbf { 7 0 \% }}$ \\
\hline EDUCATION LEVEL & $\mathbf{1 0 0 \%}$ \\
\hline
\end{tabular}

Table B:- Analysis Of Structureal Dimensions Of Banks

\begin{tabular}{|c|c|}
\hline LEVEL OF MANAGEMENT OF BANK & PERSENTAGE \\
\hline TOP LEVEL MANAGEMENTS & $\mathbf{4 0 \%}$ \\
\hline MIDDLE LEVEL MANAGEMENT & $\mathbf{3 0 \%}$ \\
\hline BOTTOM LEVEL MANAGEMENT & $\mathbf{3 0 \%}$ \\
\hline
\end{tabular}

\section{Interpretation:-}

Since the responses of respondents reflected their perceptions in relation to the daily job practices, a descriptive analysis was performed for understanding and comparing the general atmosphere of the The banking organization. In This study we discusses on the base of Two table. First tell about the demographical percentage of employee and 
second is based on structural dimension of the Banks used in this study for getting the response . In the present study we use the data collected from $75 \%$ of male respondent and $25 \%$ of female respondents in which all respondent are educated. We include all type of employees in respondents.40\% respondents of top level management and 30\% respondents are from the middle and bottom level .In regard to assessing the structural dimensions were calculated individually, and then, their averages were computed to understand the differences in structural dimensions of banking industry as this type of analysis preferred in similar studies, though there was no clearly distinguishable formation of any structural dimension for bank, the participants of banks perceive their organization as being more innovative. Employee of any banking organization feel the urgency for change, the change process will not have enough momentum.60\% Employee of banking industry Who wants change are ready to adjust themselves according to management direction another side $40 \%$ employee who do not want to change themselves with organization change are not in favor of OD changes. It refers specifically to the complacency level within banks. Creating a sense of urgency is linked to the planning phase of change. Looking the change process it is evident how important the planning element of change is. If planning is not properly done the whole process of change is negatively affected. Change is the process starting off where the bank is today and where it want to be in future.

\section{Finding and Suggestions:-}

The research implied the importance of the creation of supportive work atmosphere of banking organizations to function in line with modern OD principles. The nature of the work was of importance for atmosphere formation. The culture of innovation had relatively lesser level of relation with atmospheric variables in compare to supportive culture that was because innovative culture requires considerably different type of formation in terms of focusing on the enrichment of the inspired abilities of banking organization employee. This implied that modern type of culture requires much higher degree of freedom and autonomy for introducing, discussing and practicing new and even awkward ideas in banking organizations.

\section{Conclusion:-}

In This Study Firstly you need to communicate the OD strategic significance of the change to all employees with the use of multiple mediums stating the reasons and necessity of change. Change is associated with competitive realities in banking industry and employees need to be aware of these realities. Secondly, Top management need to be aware of the principles of change management and apply these principles in the forms of transformational level. Management need to create a vision of the future, communicate the vision with their employee. In this study the analysis of respondents bank employees was presented on the basis of the banks in which they are working. The result shows that public sector bank employees are not much better when compared to other forms of banks in NCR Region of Haryana. The determinants "Performance appraisal", "Image of your bank", "Training and development" and "Employee grievance handling" are the areas to be focused upon immediately to improve the level of banking organizational atmosphere structure, chain of command, coordination mechanism, and communication systems enhance the performance of employees. Therefore the banking organization should work more on building effective structures, just to give clarity about the roles and responsibility to the executives. More the executives are clear about their roles and responsibilities, greater they get job satisfaction.

\section{Reference:-}

1. Ansoff, I.H. (1990), Implanting Strategic Management, Prentice Hall International, Ltd. London

2. Barr, P.S., Stimpert, J.L. and Huff, A.S. (1992) "Cognitive Change, Strategic Action, and Organizational Renewal”, Strategic Management Journal, 13 (Special Issue), pp. 15-36.

3. Beer, M. and Eisenstat, R.A. (1996) "Developing an organization capable of implementing strategy and learning", Human Relations, 49 (5), pp. 597-617. I

4. Beer, M. Eisenstat, R.A. and Spector, B. (1990) "Why Change Programs Don't Produce Change", Harvard Business Review, 68 (6), pp. 158-166. |

5. Blumenthal, B. and Haspeslagh, P. (1994) "Toward a Definition of Corporate Transformation", Sloan Management Review, 35 (3), pp. 101-106. | Boeker, W. (1997) "Strategic change: The influence of managerial characteristics and organizational growth", Academy of Management Journal, 40 (1), pp. 152-170. | Burdett, J.O. (1999) "Leadership in change and the wisdom of a gentleman", | Participation \& Empowerment: An International Journal, 7 (1), pp. 5-14. |

6. Organizational culture and climate -Ashkanasy, N. M. \& Jackson, C. R. A. Handbook of Industrial, Work and Organizational Psychology - Anderson. 